\title{
Analisis Kelayakan Investasi Pada Budidaya Karamba Jala Apung (KJA) Ikan Kerapu Di Kepulauan Karimunjawa Kabupaten Jepara
}

\author{
Suryono $^{1}$, Ria Azizah TN${ }^{1}$, Edi Wibowo Kushartono ${ }^{1}$, Raden Ario ${ }^{1 *}$, Gentur Handoyo ${ }^{2}$ \\ ${ }^{1}$ Departemen Ilmu Kelautan, Fakultas Perikanan dan Ilmu Kelautan, Universitas Diponegoro \\ ${ }^{2}$ Departemen Oseanografi, Fakultas Perikanan dan Ilmu Kelautan, Universitas Diponegoro \\ Kampus Tembalang, Semarang 50275 Telp/Fax. 024-7474698 \\ Email : ario_1960@yahoo.com
}

\begin{abstract}
Abstrak
Kajian Investasi budidaya ikan kerapu di Karimunjawa adalah salah satu usaha guna menumbuhkan promosi investasi di wilayah studi. Kajian ini akan membuat peluang investasi menjadi lebih fokus dan tajam baik dari segi sektor maupun lokasinya, sehingga akan memudahkan investor guna merealisasikan rencana bisnisnya. Studi ini akan memberikan detail informasi kepada investor tentang peluang bisnis pada budidaya ikan kerapu yang sangat layak dilakukan sehingga dapat meningkatkan pertumbuhan ekonomi masyarakat pesisir dan wilayah kabupaten Jepara pada umumnya. Metode yang digunakan adalah metode survei. Peluang Investasi dianalisa secara deskriptif. Hasil kajian menunjukan bahwa berdasakan potensi alam, fasilitas infrastruktur produksi, nilai ekonomi serta aspek financial maka kelayakan investasi adalah sangat prospektif dan berpeluang untuk sukses. Analisis financial menunjukan bahwa investasi pada budidaya ikan kerapu di Karimunjawa adalah sangat layak untukdirealisasikan bagi investor. Budidaya ikan kerapu Tikus (Cromileptis altivelis)adalah paling prospektif, dimana nilai Net Present Value (NPV)> 0,yaitu 1,772,764,729, dan Profitability Index (PI) lebih besar dari 1, yaitu 5,543291036. Payback Periodadalah 2.82 tahun, jika tidak mempertimbangkan nilai uang (Discount Factors) dan 3.65 tahun jika mempertimbangkan nilai uang. Sedangkan untuk budidaya ikan kerapu bebek(Ephinephelus fuscoguttatus), Net Present Value (NPV)> 0 yaitu 69,938,924, - dan Profitability Index (PI) lebih besar dari 1, yaitu 1,20558783. (Pay Back Period) adalah 4,13tahun apabila tidak mempertimbangkan nilai uang (Discount Factor), sedangkan apabila mempertimbangkan nilai uang maka menjadi and 4.64 tahun. Dari analisis yang dilakukan, maka dapat disimpulkan bahwa meskipun kedua spesies ikan kerapu layak investasi, tetapi ikan kerapu tikuspaling layak investasi, sedangkan ikan kerapu macansebagai produk sampingan investasi, yaitu dengan memanfaatkan sisa pakan yang tidak digunakan dalam budidaya ikan kerapu tikus, sehingga hasilnya akan dapat maksimal. Keseluruhan aspek yang dikaji menunjukan bahwa budiddaya ikan kerapu di Kepulauan Karimunjawa adalah layak investasi
\end{abstract}

Kata Kunci : Investasi, Kerapu, Budidaya

Abstract

The study of feasibility floating cage culture of grouper fish investment in Karimunjawa is one of the efforts for investment promotion in the studied region. This study will make the investment opportunities become more focus and sharp, both sectoral and location, so it will be easier for investors to execute their investment interest. The purpose of this study, is to provide initial information for investors about business opportunities of grouper fish farming as a very feasible investment opportunities so that can boost the economy of the region and the society of Jepara Regency. The method used in this study was survey method, descriptive analysiswas conducted to see a of investment opportunities. Based on potential natural resources, location, infrastructure facilities, production, economy value, and financial aspect, the results of study concluded that the overall investment is highly prospective and has a fairly high chance to success. The financial analysis showed that investment in grouper fish cultivation in jepara regency is very feasible as a business investment for the investors. Humpback or Polka dot grouper (Cromileptis altivelis) culture is highly prospective and has a fairly high chance. This can be seen from the Net Present Value (NPV) > 0 is equal to 1,772,764,729, and Profitability Index (PI) value greater than 1, which is 5,543291036. While the longer the period the funds invested will return (Payback Period) is 2.82 years if the without considering the time value of money (Discount Factors) and 3.65 years when considering the time value of money. Whereas, for Brown marbled grouper (Ephinephelus fuscoguttatus), the Net Present Value (NPV) > 0 is equal to

\footnotetext{
*Corresponding author

http://ejournal.undip.ac.id/index.php/buloma

Diterima/Received : 22-06-2017

buloma.undip@gmail.com

Disetujui/Accepted : 04-08-2017
} 
69,938,924, - and Profitability Index (PI) greater than 1, which is 1,20558783. While the longer period the funds invested will return (Pay Back Period) are 4,13 year if without considering the time value of money (Discount Factors) and 4.64 years when considering the time value of money. From the analysis it can be concluded that all these choices on the investment plan is feasible to run and prospective advantageous. While the best option is an investment plan on investments Humback or Polka Dot grouper (Cromileptis altivelis) cultivation, Brown marbled grouper (Ephinephelus fuscoguttatus) culture whereas it is only a sideline activity and only utilize food wastes are left, so the whole will be able to deliver optimal results in grouper culture.All examined aspects of Grouper cultivation in karimunjawa gave results that investment activity is able to be executed. The financial analysis shows that investment in grouper fish cultivation in jepara regency is very feasible to be a business investment for the investors.

Keywords : Investment, Gouper, Feasibility

\section{PENDAHULUAN}

Kabupaten Jepara mempunyai garis pantai sepanjang 82,73 km, termasuk Kepulauan Karimunjawa. (Bappeda Jepara, 2010 ). Karimunjawa adalah kecamatan pesisir pulaupulau kecil di Kabupaten Jepara. Kepulauan Karimunjawa disamping dikenal sebagai kawasan Taman Nasionl Laut, merupakan daerah destinasi wisata bahari nasional, maka perairan lautnya memiliki potensi untuk dikelola sebagai lokasi budidaya Karamba Jala apung (KJA) ( BTN Karimunjaawa, 2010). Perairan Karimunjawa memenuhi spesifikasi perairan yang bersih untuk budidaya kerapu dan rumput laut (Tistiantoro, 2006; Ariyati et al., 2007). Pengembangan budidaya laut merupakan usaha meningkatkan produksi sekaligus merupakan langkah pelestarian kemampuan lingkungan yang dapat mengimbangi cara penangkapan ikan (Mayunar et al., 1995). Komoditas laut komersial seperti ikan kerapu bebek (Cromileptes altivelis)dan kerapu macan (Epinephelus fuscogutattus) memiliki prospek pasar yang baik dan memiliki nilai ekonomis tinggi dan banyak dibudidayakan di perairan laut Indonesia (Sugama, 2001). Bidang usaha budidaya Karamba jala apung (KJA) ikan kerapu merupakan salah satu peluang usaha yang mempunyai prospek ekonomi dan finansial yang baik dan layak untuk dikembangkan di kepulauan Karimunjawa Kabupaten Jepara. Hal ini dikarenakan sebagian besar wilayahnya terdiri atas perairan laut yang memiliki potensi sumberdaya laut yang tinggi, tersedianya prasarana dan sarana baik fisik kewilayahan maupun sumberdaya perikanan yang cukup memadai, tersedianya pasar potensial, serta adanya dukungan dari masyarakat dan pemerintah. Kebijakan pemerintah untuk mendorong munculnya industri perikanan hanya dapat dihadirkan jika industri budidaya perikanan terbukti memiliki nilai ekonomi yang tinggi (Ratna , et al, 2014) .Pengembangan budidaya karamba jala apung ikan kerapu sebagai salah satu usaha perikanan, perlu dilakukan pengkajian mengenai kelayakan finansial(Meutia,2010). Guna mengetahui sejauh mana pengusahaan ikan kerapu mampu memberikan keuntungan serta apakah usaha telah memenuhi kriteria investasi, maka perlu dilakukan analisis kelayakan usaha.Dengan melakukan analisis tentang kelayakan usaha budidaya ikan kerapu diharapkan dapat mendorong peningkatan ekonomi masyarakat pesisir dan pulau-pulau kecil di Kepulauan Karimunjawa Kabupaten Jepara.

\section{METODE PENELITIAN}

Metode yang dipergunakan dalam penelitian ini adalah perpaduan antara metode deskriptif dan metode kausal, yaitu melihat secara deskriptif implementasi investasi dan analisis peluang apakah investasi yang telah ada dapat ditingkatkan sesuai dengan potensi yang dimiliki di lokasi studi. Kebutuhan data diperoleh melalui pengumpulan data sekunder dan primer.Jenis data yang digunakan dalam penelitian ini adalah primer dan datasekunder.Data primer adalah data yang dikumpulkan dan diolah oleh peneliti danlangsung diperoleh dari objek yang diteliti.Pengumpulan data primer diperolehmelalui kuisioner, wawancara dengan responden, dan pengamatan langsung dilapang.Kuisioner digunakan pada saat wawancara dan pengamatan. Datasekunder adalah data yang pengumpulannya dilakukan oleh pihak lain seperti,Badan Pusat Statistik, Departemen-departemen dan instansi pemerintah lainnya(Mubyarto dan Soeratno 1978). Data primer diperoleh dari pelaku usaha yang telah ada baik di tingkat masyarakat maupun perusahaan-perusahaan yang bergerak dalam memproduksi dan perdagangan ikan kerapu.Metode pengumpulan data menggunakan metode dokumentasi, yaitu mencari data mengenai hal-hal atau variabel yang diperlukan antara lain: 1). Data keadaan umum wilayah 
berupa administrasi, geografi, demografi, biofisik dan infrastruktur; 2). Data Jepara Dalam Angka, 3). Data kondisi, potensi, sumberdaya kelautan dan aktivitas ekonomi; 4). Data perkembangan produksi dan penjualan komoditi-komoditi kelautan/ perikanan daerah setempat serta nilai ekspor maupun perkembangan ekspor komoditi yang akan diunggulkan; serta 5). Data-data yang terkait dengan analisis finansial investasi terhadap bisnis prospektif.Data kuantitatif dan informasi yang telah dikumpulkan diolah dengan menggunakan komputer program Microsoft Excel dan disajikan dalam bentuk tabulasi yang digunakan untuk mengklasifikasikan data yang ada serta mempermudah dalam melakukan analisis data. Data kuantitatif meliputi biaya biaya yang dikeluarkan perusahaan mencakup biaya investasi dan biaya operasional serta penerimaan dari hasil penjualan ikan kerapu macan.Sedangkan untuk data kualitatif disajikan dalam bentuk deskriptif. Data kualitatif merupakan hasil analisis terhadap aspek pasar, aspek teknis, aspek hukum, dan aspek social ekonomi dan lingkungan.

Selanjutnya data dianalisis guna mengetahui kelayakan investasi budidaya karamba jala apung ikan kerapu. Kriteria kelayakan investasi yang digunakan antara lain melalui perhitungan Net Present Value (NPV); Net B/C Ratio, Internal Rate of Return (IRR); Rate of Return On Investment (ROI); dan Payback Period (PBP) (Gittinger, 1986; Kuntjoro,2002)

\section{HASIL DAN PEMBAHASAN \\ Potensi Sumberdaya Alam}

Potensi sumberdaya alam yang dimiliki Kepulauan Karimunjawa adalah lokasi yang sesuai peruntukannya serta memenuhi syarat teknis dan ekologis untuk budidaya ikan kerapu. Persyaratan tersebut merupakan faktor kunci yang menentukan keberhasilan budidaya ikan kerapu. Sesuai dengan Surat Keputusan Dirjen Perlindungan Hutan dan Konservasi Alam Kementrian Kehutanan No 28/IV-Set/2012, Tentang zonasi Taman Nasional Karimunjawa. Ruang yang tersedia untuk kegiatan budidaya adalah diZona pemanfaatan budidaya (Marineculture Utilization zone) seluas.1.370,729 Ha, meliputi perairan pulau Karimunjawa, perairan pulau Kemujan, perairan pulau Menjangan Besar, perairan pulau Parang, perairan pulau Nyamuk dan perairan pulau Karang Besi bagian utara.Kesesuaian lokasi untuk kegiatan budidaya ikan kerapu dapat dilihat dari hasil survey, yang menunjukan adanya aktivitas budidaya KJA.yaitu: di Pulau Karimunjawa (60 unit),Pulau Menjangan Besar (40 unit), Pulau Kemujan (26 unit), Pulau Parang (20 unit) dan Pulau Nyamuk (20 unit).Hasil survey juga menemukan lokasi daerah pengembangan usaha baru yaitu P Sambangan (15 unit) dan Pulau Genting (2 Unit).

Selanjutnya dari lokasi yang sesuai dengan peruntukannya guna budidaya keramba jala apung ikan kerapu, maka dengan pertimbangan keamanan dan kemudahan dalam operasional karamba jaring apung maka sebaiknya lokasi yang ideal adalah berada pada jarak $1 \mathrm{~km}$ dari garis pantai (Imanto et al., 1995). Triskiantoro (2006) merekomendasikan lokasi yang sesuai untuk kegiatan budidaya ikan kerapu seperti yang disajikan pada Gambar 1 dan Tabel 1. Tingkat kelayakan lokasi budidaya laut yang potensial dikembangkan untuk budidaya ikan dalam karamba jaring apung seluas 150,14 haPengembangan usaha budidaya diharapkan tetap memperhatikan prinsip kelestarian dan keberkelanjutan. Untuk itu, potensi yang ada sebaiknya tidak dimanfaatkan seluruhnya, tetapi disediakan area yang berfungsi sebagai penyangga yang dapat menekan efek penurunan kualitas lingkungan. Area penyangga ini dapat dibuat dengan mengatur jumlah unit karamba. Selanjutnya Radiarta et al.(2004) menyarankan untuk penempatan jumlah unit karamba jaring apung yang ideal dalam zona budidaya tidak lebih dari $10 \%$ dari luas ideal. Berdasarkan pertimbangan tersebut maka jumlah karamba jaring apung yang dapat dioperasionalkan di lokasi dengan klasifikasi kesesuaian lahan (S1) mencapai 2.252 unit dan pada lahan dengan klasifikasi sesuai bersyarat (S2) sebanyak 1.042 unit. Untuk luasan 1 ha dapat dimanfaatkan secara efektif untuk 15 unit karamba apung, dengan ukuran $8 \times 8$ meter per unit karamba. Setiap unit karamba berisi 4 petak jaring apung masingmasing berukuran $3 \times 3 \times 3 \mathrm{~m}$. dengan padat tebar $20 \mathrm{ekor} / \mathrm{m} 3$.

\section{Sarana Dan Prasarana Investasi}

Karimunjawa telah memiliki fasilitas sarana dan prasarana yang memadai guna tumbuhnya investasi. Secara lebih rinci disajikan pada Tabel 2.

\section{Aspek Produksi}

Kegiatan produksi dilakukan dengan memelihara ikan kerapu dalam KJA.Ikan kerapu merupakan salah satu jenis ikan yang layak untuk dibudidayakan di karamba jala apung (Pramu, 
2000, Ismail, 2002 dan Kordi, 2005). Lama pemeliharaan ikan Kerapu Macan 12 bulan mulai dari tahap pendederan, penggelondongan, dan pembesaran dengan asumsi laju sintasan 60\%, dipanen pada bobot 500 gr/ekor. Ikan dijual dalam keadaan hidup di lokasi panen (pemeliharaan) dengan harga rata-rata sebesar Rp. 117.000,-/kg. Sedangkan untuk pemeliharaan ikan Kerapu bebekLama 14 bulan dengan sintasan, $60 \%$, dipanen dalam keadaan hidup di lokasi panen (pemeliharaan) dengan harga rata-rata sebesar Rp. $350.000,-/ \mathrm{kg}$. (Nainggolan et al., 2003 dan Wardana, 1994).

\section{Kelayakan Finansial}

Muara dari suatu bisnis yang dijalankan pada akhirnya akan menuju pada aspek keuangan. Seluruh elemen kegiatan yang dibahas pada aspek pasar, teknis, dan manajemen akan dikuantifikasi dalam satuan uang untuk mengetahui besar kebutuhan dana dan bagaimana memenuhi kebutuhan dana tersebut(Gittinger,1986;dan Kuntjoro,2002). Disamping itu proyeksi hasil operasi akan menentukan sejauh mana manfaat secara finansial dapat diperoleh melalui bisnis tersebut.Untuk mengetahui kelayakan investasi dari aspek keuangan dibutuhkan proyeksi laporan keuangan investasi budidaya kerapu . Hasil perhitungan kelayakan finansial (Tabel 3).

Berdasarkan hasil analisis dapat diketahui bahwa investasi budidaya kerapu tikussangat prospektif dan punya peluang yang cukup tinggi untuk dapat berhasil dan ditingkatkan omsetnya dimasa-masa yang akan datang. Hal ini terlihat dari Net Present Value (NPV) atau selisih antara Present Value dari Net Cash Flow dan Initial Investment (Io) > 0yaitu sebesar Rp. 1.772.764.729 serta Profitability Index (PI) nilai sekarang penerimaan-penerimaan kas bersih di masa datang dengan nilai investasi awal lebih besar dari 1, yaitu 5.543291036.Sedangkan lama periode dana yang diinvestasikan akan kembali (pay back period) adalah 2.82 tahun jika tanpa mempertimbangkan nilai waktu uang (diskon faktor) dan 3.65 tahun jika mempertimbangkan nilai waktu uang.

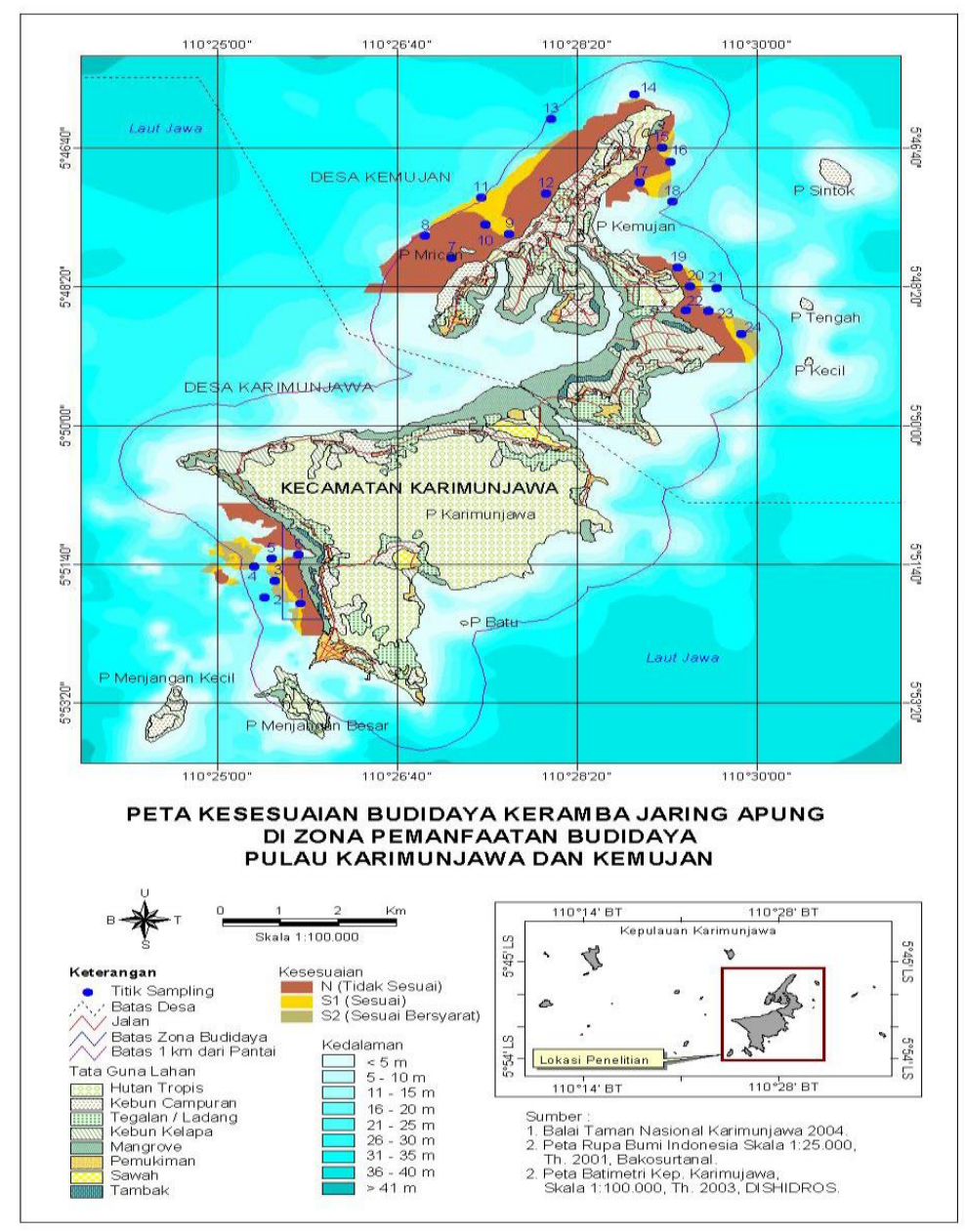

Gambar 1. Lokasi Budidaya KJA ikan Kerapu di Karimunjawa 
Tabel 1. Lokasi Penempatan KJA Untuk Budidaya Ikan kerapu Di Karimunjawa

\begin{tabular}{|c|c|c|c|c|c|c|c|}
\hline \multirow{2}{*}{ Lokasi } & \multirow{2}{*}{ Nama Dusun } & \multicolumn{3}{|c|}{ Longitude (E) } & \multicolumn{3}{|c|}{ Latitude (S) } \\
\hline & & Derajat & Menit & Detik & Derajat & Menit & Detik \\
\hline 1 & Jatikerep & 110 & 25 & 46,41 & 5 & 52 & 8,68 \\
\hline 2 & Jatikerep & 110 & 25 & 26,40 & 5 & 52 & 4,08 \\
\hline 3 & Jatikerep & 110 & 25 & 32,19 & 5 & 51 & 51,91 \\
\hline 4 & Jatikerep & 110 & 25 & 20,89 & 5 & 51 & 41,40 \\
\hline 5 & Jatikerep & 110 & 25 & 30,21 & 5 & 51 & 35,71 \\
\hline 6 & Jatikerep & 110 & 25 & 45,51 & 5 & 51 & 33,19 \\
\hline 7 & Telaga & 110 & 27 & 10,44 & 5 & 47 & 59,42 \\
\hline 8 & Telaga & 110 & 26 & 55,71 & 5 & 47 & 43,29 \\
\hline 9 & Telaga & 110 & 27 & 42,73 & 5 & 47 & 42,00 \\
\hline 10 & Telaga & 110 & 27 & 29,16 & 5 & 47 & 35,26 \\
\hline 11 & Telaga & 110 & 27 & 27,05 & 5 & 47 & 15,86 \\
\hline 12 & Telaga & 110 & 28 & 3,03 & 5 & 47 & 12,98 \\
\hline 13 & Batulawang & 110 & 28 & 5,70 & 5 & 46 & 19,09 \\
\hline 14 & Batulawang & 110 & 28 & 52,39 & 5 & 46 & 1,41 \\
\hline 15 & Batulawang & 110 & 29 & 7,51 & 5 & 46 & 39,97 \\
\hline 16 & Batulawang & 110 & 29 & 12,04 & 5 & 46 & 49,83 \\
\hline 17 & Batulawang & 110 & 28 & 55,34 & 5 & 47 & 4,81 \\
\hline 18 & Batulawang & 110 & 29 & 13,20 & 5 & 47 & 18,45 \\
\hline 19 & Telaga & 110 & 29 & 16,36 & 5 & 48 & 6,12 \\
\hline 20 & Jelamun & 110 & 29 & 23,02 & 5 & 48 & 6,12 \\
\hline 21 & Jelamun & 110 & 29 & 37,93 & 5 & 48 & 20,95 \\
\hline 22 & Jelamun & 110 & 29 & 20,68 & 5 & 48 & 36,68 \\
\hline 23 & Jelamun & 110 & 29 & 33,46 & 5 & 48 & 37,76 \\
\hline 24 & Jelamun & 110 & 29 & 51,75 & 5 & 48 & 54,36 \\
\hline
\end{tabular}

Tabel 2 . Sarana dan Prasarana Investasi di Kepulauan Karimunjawa

\begin{tabular}{clcl}
\hline No & Fasilitias & Total & Informasi \\
\hline 1 & Hotel dan resort & 6 & Swasta dan Pemerintah \\
2 & Homestay & 16 & Masyarakat \\
3 & Komunikasi & 1 & TELKOM \\
4 & Air Bersih & 4 & PDAM Swasta \\
5 & Listrik & 2 & PLTD \\
6 & Transportasi Laut & 3 & KMP Siginjai and KM Kartini I, Express Bahari \\
& Darat & 11 & Mobil \\
& Udara & 1 & CV. Susi Air \\
& Pelabuhan & 6 & Pemerintah dan Swasta \\
& Bandara & 1 & Pemerintah \\
7 & Kesehatan & 1 & Vilage Hospital (Puskesmas) \\
8 & Keamanan & 5 Kantor & Polsek, Koramil, Polisi Pantai, TNI Angkatan Laut, dan Polisi BTN \\
9 & Tempat Ibadah & 38 & Masjid, Surau dan Gereja \\
10 & Sekolah & 18 & Dasar, SMP, SMA-SMK-MA \\
11 & Pasar & 1 & Di Karimunjawa \\
12 & Olah Raga & 16 & Sepak Bola dan voley ball \\
\hline
\end{tabular}

Sumber : Jepara dalam angka (2015) 
Tabel 3. Proyeksi Arus Kas Bersih Investasi Budidaya Kerapu Tikus

\begin{tabular}{crrr}
\hline Periode (Tahun) & Arus Kas Bersih & Faktor Diskon & \multicolumn{2}{c}{ Present Value Arus Kas Bersih } \\
\hline & A & b & $\mathbf{c}=\mathbf{a : b}$ \\
Pra Operasional & $(390.190 .000)$ & & \\
I & 110.434 .438 & 1.1727 & $(390.190 .000)$ \\
II & 139.615 .841 & 1.37522529 & 94.171 .091 \\
III & 171.807 .181 & 1.612726698 & 101.522 .159 \\
IV & 207.342 .205 & 1.891244598 & 106.632 .675 \\
V & 3.883 .651 .837 & 2.21786254 & 109.632 .675 \\
Net Present Value (NPV) & & & 1.751 .078 .692 \\
Profitability Index (PI) & & & 1.772 .764 .729 \\
Internal Rate of Return (IRR) & & & 5.543291036 \\
Payback Period & & $76 \%$ \\
Discounted Payback Period & & & 2.82 \\
\hline
\end{tabular}

Tabel 4. Proyeksi Arus Kas Bersih Investasi Budidaya Kerapu Macan

\begin{tabular}{|c|c|c|c|}
\hline Periode (Tahun) & Arus Kas Bersih & Faktor Diskon & Present Value Arus Kas Bersih \\
\hline & $\mathbf{A}$ & B & $\mathbf{c}=\mathbf{a}: \mathbf{b}$ \\
\hline Pra Operasional & $(340.190 .000)$ & & $(340.190 .000)$ \\
\hline I & 70.399 .288 & 1.1727 & 60.031 .797 \\
\hline II & 68.745 .347 & 1.37522529 & 49.988 .426 \\
\hline III & 68.228 .796 & 1.612726698 & 42.306 .484 \\
\hline IV & 68.927 .330 & 1.891244598 & 36.445 .487 \\
\hline $\mathrm{V}$ & 490.938 .802 & 2.21786254 & 221.356 .731 \\
\hline \multicolumn{3}{|c|}{ Net Present Value (NPV) } & 69.938 .924 \\
\hline \multicolumn{3}{|l|}{ Profitability Index (PI) } & 1.20558783 \\
\hline \multicolumn{3}{|c|}{ Internal Rate of Return (IRR) } & $23 \%$ \\
\hline \multicolumn{3}{|l|}{ Payback Period } & 4.13 \\
\hline \multicolumn{3}{|c|}{ Discounted Payback Period } & 4.64 \\
\hline
\end{tabular}

Berdasarkan hasil analisis dapat diketahui bahwa Budidaya Ikan Kerapu Macan prospektif dan punya peluang yang tinggi untuk dapat berhasil dan ditingkatkan omsetnya dimasa-masa yang akan datang. Hal ini terlihat dari Net Present Value (NPV) atau selisih antara Present Value dari Net Cash Flow dan Initial Investment (Io) > 0yaitu sebesar Rp. 69.938.924,- serta Profitability Index (PI) nilai sekarang penerimaan-penerimaan kas bersih di masa datang dengan nilai investasi awal lebih besar dari 1, yaitu 1.20558783. Sedangkan lama periode dana yang diinvestasikan akan kembali (pay back period) adalah 4.13 tahun jika tanpa mempertimbangkan nilai waktu uang (diskon faktor) dan 4.64 tahun jika mempertimbangkan nilai waktu uang.

\section{Keputusan Pilihan Investasi Terbaik}

Nilai investasi budidaya kerapu bebek lebih besar dibandingkan dengan investasi budidaya kerapu macan. Payback Period investasi budidaya kerapu bebek lebih kecil dibanding investasi budidaya kerapu macan, Hal ini berarti bahwa investasi budidaya kerapu bebek lebih cepat pengembalian modalnya dibanding investasi budidaya kerapu macan. IRR dan PI investasi budidaya kerapu bebek lebih besar daripada investasi budidaya kerapu macan. Hal ini menunjukkan bahwa budidaya kerapu bebek memiliki tingkat keuntungan lebih besar dibanding investasi budidaya kerapu macan. NPV merupakan faktor yang paling menentukan dalam menilai layak tidaknya suatu usulan investasi. Proyek dengan NPV positif dan terbesar dari berbagai usulan proyek adalah yang paling layak untuk dilaksanakan. NPV kedua pilihan investasi tersebut di atas menunjukkan angka positif yang berarti ketiganya layak dijalankan karena akan menguntungkan. Sedangkan nilai NPV terbesar adalah pada rencana kegiatan investasi budidaya kerapu bebek.

Dari analisis dapat disimpulkan bahwa kesemua pilihan rencana investasi tersebut di atas adalah layak untuk dijalankan dan prospektif 
Tabel 5. Perbandingan Kriteria Investasi Budidaya Kerapu Bebek dan Kerapu Macan.

\begin{tabular}{lrr}
\hline & Budidaya Kerapu Bebek & Budidaya Kerapu Macan \\
\hline Dana Investasi & Rp. 390.190.000 & Rp. 340.190.000 \\
Net Present Value (NPV) & 1.772 .764 .729 & 69.938 .924 \\
Profitability Index (PI) & 5.543291036 & 1.20558783 \\
Internal Rate of Return (IRR) & $76 \%$ & $23 \%$ \\
Payback Period & 2.82 & 4.13 \\
Discounted Payback Period & 3.65 & 4.64 \\
\hline
\end{tabular}

menguntungkan. Sedangkan pilihan terbaik rencana investasi adalah Investasi budidaya kerapu bebek, sedangkan budidaya kerapu macan sifatnya hanya merupakan kegiatan tambahandengan memanfaatkan limbah-limbah pakan yang tersisa, sehingga secara keseluruhan akan dapat memberikan hasil yang optimal pada budidaya kerapu.

\section{KESIMPULAN}

Hasil analisis finansial menunjukkan bahwa investasi di bidang usaha budidaya karamba jala apung ikan kerapu di kepulauan Karimunjaawa Kabupaten Jepara sangat fisibel untuk dijadikan usaha.

\section{UCAPAN TERIMA KASIH}

Studi kelayakan investasi budidaya ikan kerapu di Karimunjawa terselenggara atas dukungan pendanaan APBD Kabupaten Jepara ,padaBadan Penanaman Modal dan PerijinanTerpadu untuk itu ucapan terima kasih disampaikan. Terima kasih juga disampaikan kepada Anik Susila, SP,MSi; Drs. Zainul Arifin ; Azhar(Dewan Riset Daerah Kabuapen Jepara) dan Sekar Wibowo(karyaawan FPIK Undip) yang telah membantu survey lapangan,enumerasi kuestioner serta pengolahan data .

\section{DAFTAR PUSTAKA}

Ariyati, R. Wisnu, Lachmuddin Sya'rani, Endang Arini. 2007. Analisis Kesesuaian Perairan

Pulau Karimunjawa dan Pulau Kemujan sebagai Lahan Budidaya Rumput Laut Menggunakan Sistem Informasi Geografis, Master thesis, Universitas Diponegoro, Semarang

Bappeda Kabupaten Jepara (2010) RIPPDA Jepara 2010-2019

Dirjen Perlindungan Hutan dan Konservasi Alam Kementrian Kehutanan .2012, Zonasi Taman Nasional Karimunjawa
Gittinger, J. Price. 1986. Analisis Ekonomi Proyek-Proyek Pertanian. Edisi Kedua. Universitas Indonesia.

Imanto, P. T., N. Listyanto dan B. Priono. 1995. Desain dan Konstruksi Karamba Jaring Apung untuk Budidaya Ikan Laut dalam Sudradjat et al. 1995.Prosiding Temu Usaha Pemasyarakatan Teknologi Karamba Jaring ApungBagi Budidaya Laut. Puslitbang Perikanan. Badan Litbang Pertanian. p. 216233.

Ismail, W dan E. Pratiwi. 2002. Budidaya Laut Menurut Tipe Perairan. Warta Penelitian perikanan Indonesia.Vol. 8 No. 2 p. 8 - 12 .

Kordi KMGH. 2005. Pembesaran Kerapu Bebek di Keramba Jaring Apung.Jakarta :Penerbit Kanisius. 132 halaman.

Kuntjoro. 2002. Kelayakan Finansial Proyek. Jurusan Ilmu-ilmu Sosial Ekonomi.Fakultas Pertanian. IPB. Bogor.

Mayunar, R. Purba dan P.T. Imanto. 1995. Pemilihan Lokasi untuk Usaha Budidaya Ikan Laut dalam Sudradjat et al. 1995. Prosiding Temu Usaha Pemasyarakatan Teknologi keramba Jaring Apung bagi Budidaya Laut. Puslitbang Perikanan, Badan Litbang Pertanian. P. 179189

Meutia Sari Sulaiman, 2010. Analisis kelayaan pengusahaan Ikan Kerapu Macan di Kepulauan Seribu Propinsi DKI Jakarta

Mubyarto, dan Soeratno. 1978. Metodologi Penelitian Ekonomi. Yogyakarta: Fakultas Ekonomi, Universitas Gadjah Mada.

Nainggolan C, S Putro,dan J Haluan,. 2003. Pedoman Investasi Komoditas Kerapudi Indonesia. Jakarta: Departemen Kelautan dan Perikanan Jakarta.

Pramu Sunyoto. 2000. Pembesaran Kerapu dengan Karamba Jaring Apung. Penebar Swadaya.

Radiarta, N., S.E Wardoyo, B. Priono dan O. Praseno. 2003. Aplikasi Sistem Informasi 
Geografis untuk Penentuan Lokasi Pengembangan Budidaya Laut di Teluk Ekas, nusa Tenggara Barat.Jurnal Penelitian Perikanan Indonesia Vol. 9 No.1 p. 67 - 79.

Ratna Purwaningsih, Zainal Fanani R, Vita Shany Nugrahaeni.2014. Model optimasi perikanan budidaya laut (Studi Kasus Perairan Karimunjawa, Kabupaten Jepara). J@TI Undip, Vol IX, No 3, September 2014.

Sugama, K. 2001. Kondisi terkini sumber-daya ikan hasil budidaya dalam mendukung industrialisasi Perikanan. Materi Kuliah
Umum UGM, 2012 November 12; Jakarta. Jakarta (ID): Ditjen Perikanan Budidaya, Kemen-terian Kelautan dan Perikanan. 10p.

Triskiantoro, Fendiawan,. 2006. Analisis Kesesuaian Lokasi Budidaya karamba Jala Apung Dengan Aplikasi Sistem Informasi Geografis di Pulau Karimunjawa Dan Kemujan. Thesis Pasca Sarjana MSDP Universitas Diponegoro

Wardana. IP. 1994. Pembesaran Kerapu Dengan Keramba Jaring Apung. Penebar Swadaya. Jakarta. 